\title{
LONG-TERM VARIATIONS OF THE SOLAR WIND COMPONENTS AND THEIR TERRESTRIAL MANIFESTATIONS
}

\author{
Georgieva K. ${ }^{1}$, Kirov B. ${ }^{1}$, Obridko V.N. ${ }^{2}$ \\ ${ }^{I}$ SRTI-BAS, Sofia, Bulgaria \\ ${ }^{2}$ IZMIRAN, Troitsk, Russia
}

\section{ДОЛГОСРОЧНЫЕ ВАРИАЦИИ КОМПОНЕНТОВ СОЛНЕЧНОГО ВЕТРА И ИХ ЗЕМНЫХ ПРОЯВЛЕНИЙ}

\author{
Георгиева К. ${ }^{1}$, Киров Б. ${ }^{1}$, Обридко В.Н. \\ ${ }^{1}$ ИКИТ-БАН, София, Болгария \\ ${ }^{2}$ ИЗМИРАН, Троиик, Россия
}

Все время Земля находится в солнечном ветре - расширяющейся короне Солниа. Солнечный ветер неоднороден, он состоит из нескольких компонентов: медленный солнечный ветер вдоль гелиосферного токового слоя, высокоскоростной солнечный ветер из больших полярных корональных дыр в солнечном минимуме и из более мелких визкоширотных дыр в максимуме, корональные вымросы массы. Частота проявлений и характеристики всех этих компонентов меньются в течении 11-летнего солнечного цикла. Меняется и их вклад в геомагнитную активность. В настоящей работе мы представляем вариации относительного преобладания и характеристик компонентов солнечного ветра от цикла к циклу и оченим основные причины долгосрочных изменений геомагнитной активности.

\section{DOI: 10.31725/0552-5829-2018-103-106}

It has long been known that the geomagnetic activity (deviation of the Earth's magnetic field from its long-term averages) is caused by solar events leading to transient disturbances in the solar wind - the ever expanding solar atmosphere [1]. The geomagnetic activity roughly follows the solar activity, however there are important differences between them. Fig.1 shows the solar activity presented by the international sunspot number (black line), and the geomagnetic activity presented by the ap-index (grey line). In general, their peaks don't coincide, and ap often has of the heliospheric current sheet, rea second peak during sunspot declining phase. Besides, while sunspots fall to almost zero at sunspot minimum, ap minimum varies in a wide range.

In a previous study [2] we investigated what determines the geomagnetic activity in sunspot minimum. The current paradigm is that the level of geomagnetic activity in cycle minimum is determined by the thickness

spectively by the time that the

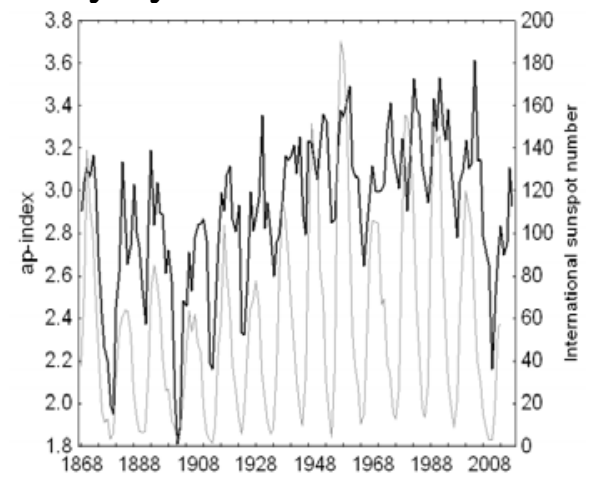

Fig. 1. 
Earth spends in its low-speed and with low geoeffectiveness plasma versus the time the Earth is out of the heliospheric current sheet and exposed to high-speed and highly geoeffective streams from superradially expanding polar coronal holes. Our results showed that this is not the case, and instead the geomagnetic activity in the last four sunspot minima has been decreasing due to the decreasing magnetic field, speed and dynamic pressure of all solar wind components.

The purpose of the present study is to investigate the long-term (cycle to cycle) variations in the geomagnetic activity and the characteristics of its solar sources.

\section{Data}

The solar wind can be categorized in different types according to its source region and its characteristics. Traditionally, 3 types of solar wind are identified: slow solar wind from the heliospheric current sheet, fast solar wind from solar coronal holes, and coronal mass ejections. There is a number of catalogues of the solar wind types. We use the catalog of Xu and Borovsky [3] kindly provided by Dr. J. Borovsky. In this catalog, one additional type is added - "sector reversal regions" which are part of the heliosheet, but we don't regard them separately as they don't differ substantially from the heliospheric current sheet in their long-term variations.

\section{Results}

Figs. 2 and 3 present the variations of the solar wind scalar magnetic field and dynamic pressure, respectively, in the three types of solar wind. In both figures, the upper panel pertains to the slow solar wind, the middle one to the highspeed solar wind, and the bottom one to coronal mass ejections. The thin solid line presents the annual averaged values of the studied parameter, the thick solid line is its 13-year moving average to filter the 11-year sunspot cycle. The international sunspot number (dotted line) is added for reference.

The magnetic field in both the slow and high speed solar wind was increasing until 1985-1990, and began decreasing after that. For the CMEs, this inversion occurred with a delay of 4-5 years. The dynamic pressure in all 3 components of the solar wind has similar behavior: continuous increase until 19851990, followed by a reversal and a decrease afterwards.

CMEs are the drivers of the most intense geomagnetic storms, however these storms are rare, except around sunspot maximum, and short-lasting. On monthly and yearly time-scales, the geomagnetic activity is determined by the geoeffectiveness of the slow solar wind and the HSS [4]. In the upper three panels of Fig. 4 the geomagnetic activity is presented during periods when the Earth is under the influence of the three solar wind types. Fig. 4 demonstrates that the annually averaged geomagnetic activity (the bottom panel) follows the geomagnetic activity caused by slow solar wind and HSS. 

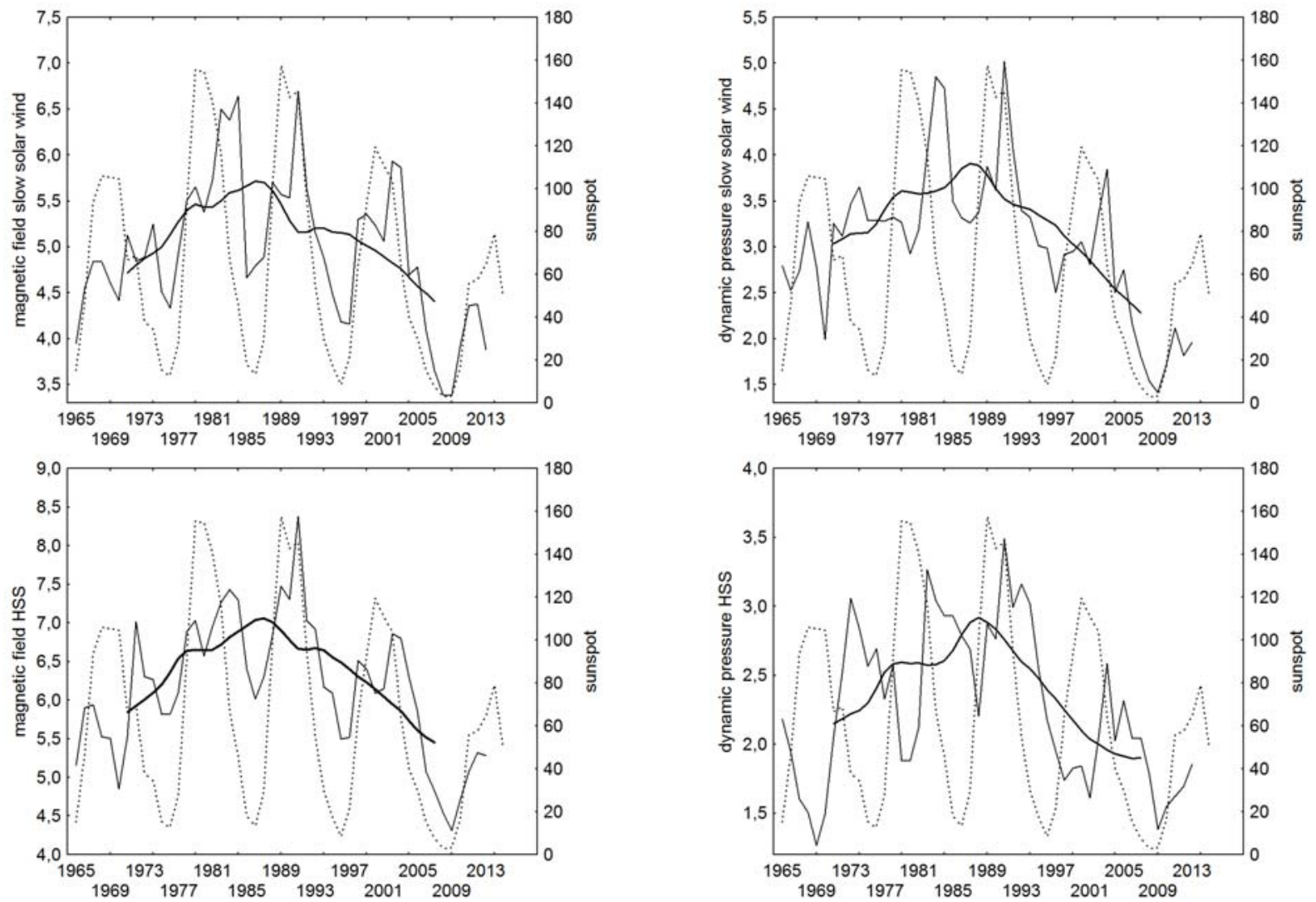

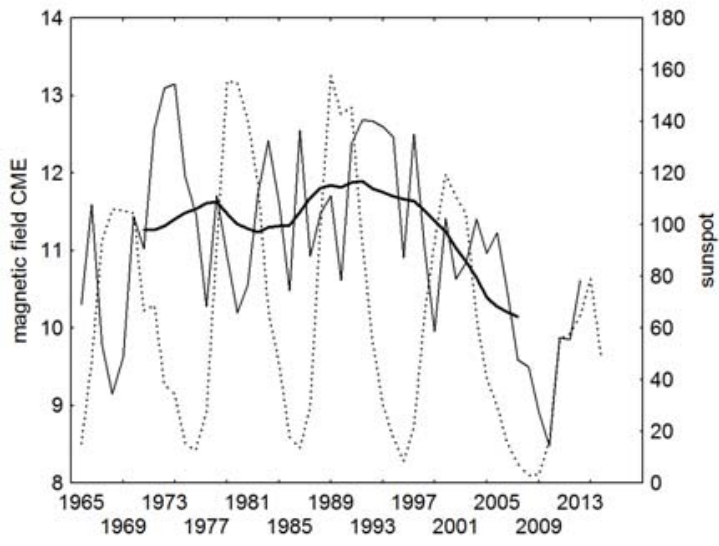

Fig. 2.

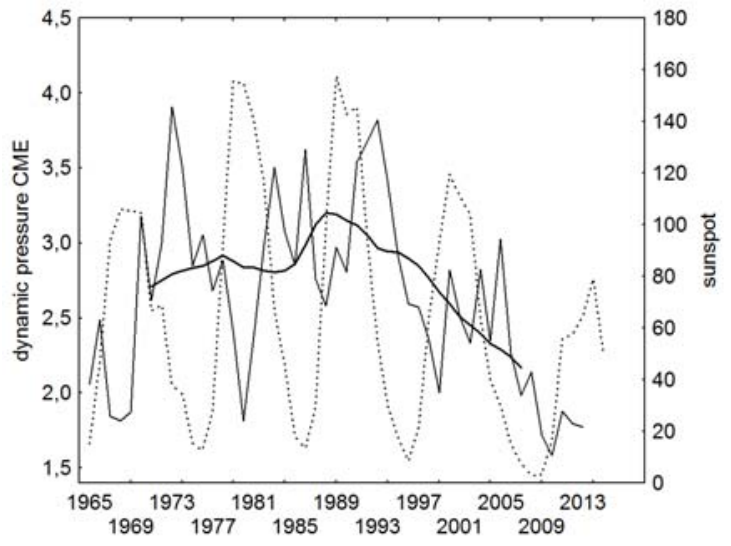

Fig. 3.

The annually averaged geomagnetic activity and the geomagnetic activity caused by slow solar wind and HSS all increase until 1985-1990, and then start decreasing. What is the reason for this? The coronal holes and the heliospheric current sheet are related to the solar global, or dipole field. It has been shown that the solar field has been decreasing since 1985-1990 [5, 6]. The upper panel of Fig. 5 is a composite plot of the solar magnetic moment calculated in [5] and complemented in [6] and by data from the Wilcox Solar Observatory (http://wso.stanford.edu/gifs/Polar.gif), and the lower panel is the 13-year averaged geomagnetic aa-index. Fig. 5 demonstrates that the geomagnetic activity which is mostly determined by the magnetic field and dynamic pressure of the slow solar wind and high-speed solar wind streams, follows the variations of the solar magnetic moment. 

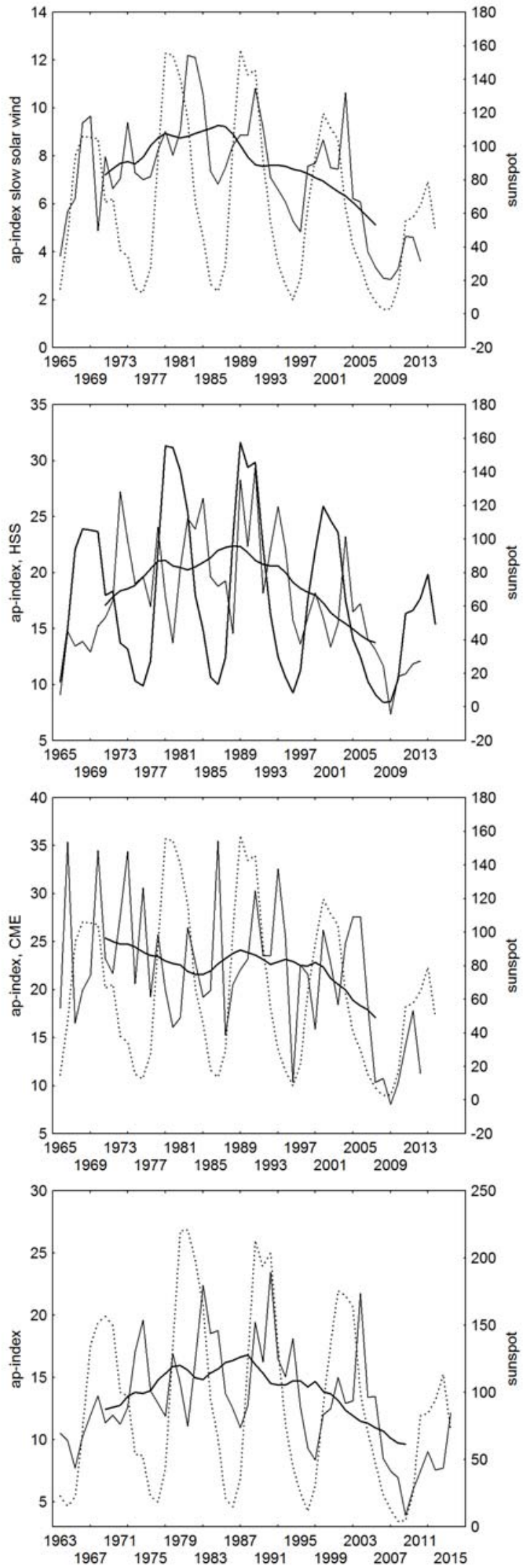

Fig. 4.
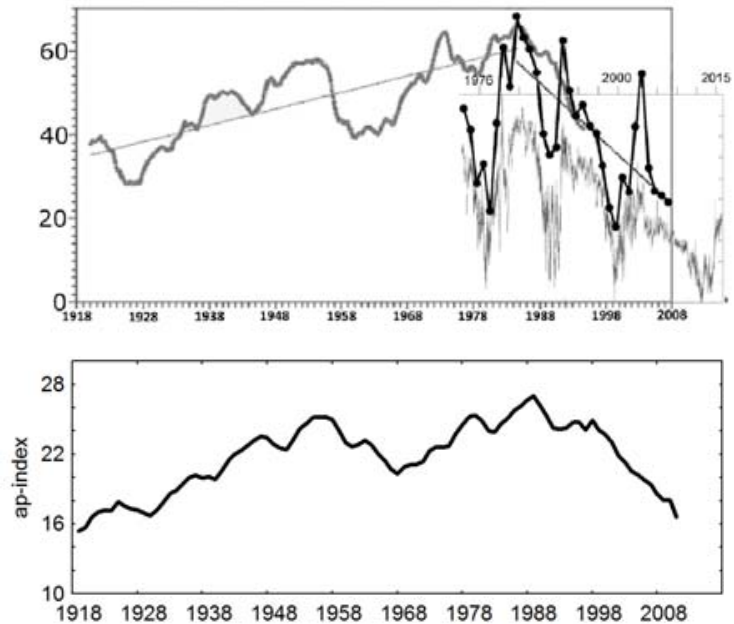

Fig. 5.

\section{Conclusion}

The increase in the solar magnetic moment observed until 1985-1990 is replaced by decrease after that, leading to decreasing magnetic field and dynamic pressure of the background and high speed solar wind, and as a result - of the geomagnetic activity.

\section{References}

1. Parker E.N. // J. Geophys. Res., 1959, 64 (11).

2. Kirov B. et al. // Geomag. and Aeron., 2015, 55 (8),

3. Xu F., Borovsky J. // J. Geophys. Res. 2015, 120 (1).

4. Richardson I.G., Cane H.V. // JSWSC doi:10151/swsc/2012003, 2012.

5. Makarov V.I., Obridko V.N., Tlatov A.G. // Astron. Zh., 2001, 78.

6. Obridko V.N., Shelting B.D. // Astron. Lett., 2009, 35 (4). 